\title{
Predictors of staging accuracy, pathologic nodal involvement, and overall survival for cT2N0 carcinoma of the esophagus
}

\author{
Esophageal Cancer Study Group Participating Centers
}

\section{ABSTRACT}

Objective: Clinical T2N0 esophageal carcinoma is a heterogenous disease frequently complicated by inaccurate staging. Incorrect staging may lead to suboptimal treatment for patients with unidentified local-regionally advanced disease. Therapeutic options for these patients remain controversial. We sought to evaluate the outcomes of patients with cT2N0 who underwent esophagectomy as either primary therapy or after neoadjuvant treatment.

Methods: This was a multi-institutional collaboration of 26 high-volume esophageal centers. Patients with complete staging who underwent elective resection from 2002 to 2012 were included. Three treatment groups were identified; primary esophagectomy, preoperative chemotherapy, and preoperative chemoradiation (CXRT). Pretreatment variables were explored for independent predictors of long-term outcomes. The primary esophagectomy subgroup was evaluated for stage migration.

Results: In total, 767 patients were evaluated; 35\% (268) had preoperative therapy (195 CXRT, 73 chemotherapy). Staging accuracy was 14\% (70/499), with pT $<2$ identified in $45 \%$ (222) and $\mathrm{pN}>0$ in 39\% (195). Preoperative treatment modality (none, CXRT, chemotherapy) was not identified as a predictor of outcome (median survival 63, 70, 71 months, respectively, $P=.956$ ). Longitudinal tumor length $>3.25 \mathrm{~cm}$ was predictive of $\mathrm{pN}+$ for the primary esophagectomy cohort as well as adenocarcinoma histology only (odds ratio 2.2 and 2.4, respectively, $P<.001$ ).

Conclusions: Current treatment options for patients with cT2NOM0 do not reveal a comparative survival advantage to preoperative therapy. Pretreatment tumor length can identify a subgroup of patients at risk for understaging $(\mathrm{pN}+)$. The incidence of overstaging suggests that organ-sparing approaches (endoscopic resection) may play a future role in appropriately selected patients. (J Thorac Cardiovasc Surg 2019;157:1264-72)

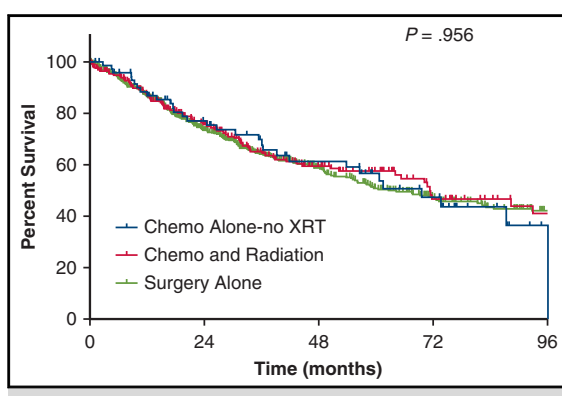

Overall survival for cT2NO patients undergoing esophagectomy, comparing treatment groups.

\section{Central Message}

Neoadjuvant therapy does not improve survival in unselected cT2N0 esophageal carcinoma. Tumor length may aide in identifying the greatest risk cohort despite inaccurate staging.

\section{Perspective}

Trimodality therapy offers the potential for long-term survival in appropriately selected patients with local-regionally advanced esophageal cancer. cT2N0 is a heterogeneous disease complicated by inaccurate staging and variable outcomes. Tumor characterization including length may allow for selection of the cohort most at risk for advanced disease, in whom trimodality therapy may afford benefit.

See Commentary on page 1273.
Despite advances in staging technology, discordance between clinical and pathologic tumor, node, and metastases staging for cT2N0 esophageal cancer remains

Funding for this work was provided by the Department of Thoracic and Cardiovascular Surgery, University of Texas MD Anderson Cancer Center.

Manuscript prepared by Scott M. Atay, MD, Arlene Correa, $\mathrm{PhD}$, and Wayne L Hofstetter, MD, on behalf of the Esophageal Cancer Study Group. Participating sites and principal investigators are listed in Appendix 1.

Received for publication June 9, 2017; revisions received Oct 1, 2018; accepted forpublication Oct 10, 2018; available ahead of print Dec 14, 2018.

Address for reprints: Scott M. Atay, MD, University of Southern California, Keck School of Medicine, 1510 San Pablo St, Suite 514, Los Angeles, CA 90033 (E-mail: smatay@gmail.com).

0022-5223/\$36.00

Copyright (c) 2018 by The American Association for Thoracic Surgery

https://doi.org/10.1016/j.jtcvs.2018.10.057 significant. ${ }^{1-5}$ Optimal therapy can range from primary endoscopic intervention, to trimodality therapy including esophagectomy, to definitive chemoradiation (CXRT). As this is a relatively small cohort of esophageal cancer patients, ${ }^{6}$ randomized controlled trials to compare different treatment strategies may not be a viable endeavor. Recently, several publications have attempted to address this group of patients, with disparate results. Studies using a retrospective

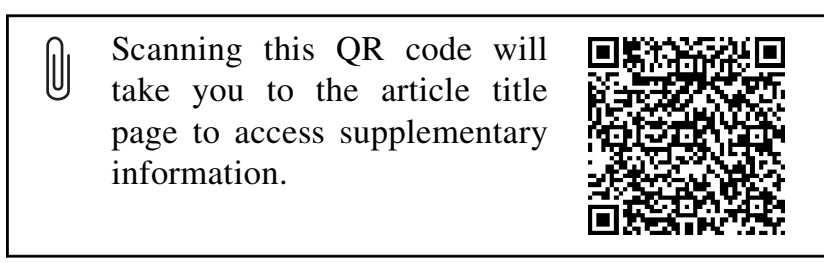



Abbreviations and Acronyms
$\mathrm{CXRT}=$ chemoradiation
EGD = esophagogastroduodenoscopy
EUS $=$ endoscopic ultrasound
LVI = lymphovascular invasion
PET = positron emission tomography

review of national databases have represented a reasonable alternative, although the outcomes may vary widely based on institutional preferences and/or center volume..$^{2,5,6}$ Therefore, a multi-institutional retrospective review of data from focused esophageal programs may represent the best evidence-based data to guide therapeutic decisions. Using an international collaborative group, we sought to evaluate patients with clinical cT2N0M0 esophageal carcinoma who received definitive surgical resection with or without preoperative therapy. Our aims were to evaluate treatment patterns within high-volume esophageal centers, describe the incidence of stage migration, compare the outcomes of various treatment approaches, and identify factors associated with low-/high-risk disease to help guide therapy.

\section{PATIENTS AND METHODS}

A multi-institutional, international collaborative group was formed comprising high-volume centers with a focus on esophageal disease. Twenty-six centers were involved in database creation, study design, and manuscript preparation. Fifteen centers contributed data included in the results presented in this manuscript (Appendix 1). Institutional review board(s) at the host and contributing centers reviewed the protocol and waived the requirement of individual patient consent.

All patients had biopsy confirmed cT2N0 esophageal carcinoma located anywhere from the proximal thoracic esophagus to the gastroesophageal junction (type I/II). Complete staging was required, including a computed tomography chest/abdomen as well as positron emission tomography (PET) or esophagogastroduodenoscopy (EGD)/endoscopic ultrasound (EUS). EUS and/or PET was not available or not used at all centers during the study period; the inclusion of either modality was at the discretion of the treating physicians. Both adenocarcinoma and squamous cell carcinoma histology were included; the adenocarcinoma cohort was analyzed as a separate subgroup. In cases in which preoperative therapy was administered, it consisted of chemotherapy alone or CXRT. The specific agents and radiation dose varied among the treating centers and were not included in the database for analysis. Cervical tumors, as well as salvage, emergent, or redo resections were excluded. All patients were required to have completed therapy by December 31, 2012, to allow adequate follow-up.

All patients underwent esophagectomy; the specific technique and extent of lymphadenectomy was at the discretion of the treating surgeon. The anastomotic locations were determined by the extent of disease, technique, and approach used.

Patients were separated into 3 groups for analysis: (1) primary esophagectomy, (2) preoperative chemotherapy, and (3) preoperative CXRT. Primary analysis included overall and recurrence-free survival comparisons across the 3 groups. Survival analyses were performed using the KaplanMeier method from the date of first therapy, comparing survival curves with the log-rank test. Secondary endpoints included evaluation of staging accuracy in patients undergoing primary esophagectomy. Univariable Cox regression analysis was performed, identifying covariates with a $P$ value of less than .25 that were then entered into a multivariable analysis. Stepwise
Wald backward elimination with and without adjustment for clustering at the institutional level using mixed models with site 2 as random effect with robust covariances was used in multivariable Cox regression analysis to identify variables predictive of overall survival. Multivariable logistic regression analysis was used to identify predictors of pathologic lymph node involvement in patients undergoing primary esophagectomy. Patientand tumor-specific variables, including age, sex, pTMN status, histology, tumor length, location, resection technique, and preoperative treatment, were included in regression models. Longitudinal tumor length was identified on preoperative EGD/EUS as well as final pathologic specimens. Analysis was performed on both cohorts (preoperative and postoperative measurements) separately. Lymphovascular invasion (LVI) was determined on final pathologic examination of resection specimens. Statistical significance was defined as $P$ values of $<.05$ and were 2-sided unless otherwise stated. Early postoperative outcomes were compared between groups. SPSS 23 software (IBM Corp, Armonk, NY) was used to perform the statistical analysis. In addition, TIBCO Spotfire $\mathrm{S}+8.2$ for Windows (TIBCO Software, Inc, Palo Alto, Calif) was used to generate recursive partitioning trees to obtain best cutoff values for continuous variables.

\section{RESULTS \\ Demographics}

A total of 767 patients with cT2N0 esophageal cancer at 15 institutions underwent esophagectomy between January 2002 and December 2012. Preoperative therapy was administered to $35 \%$ (268/767) of the study cohort; $25 \%$ (195) receiving CXRT and 10\% (73) receiving chemotherapy alone. Demographics of the cohort are included in Table 1. Most patients were men $(80 \%, 614 / 767)$, with adenocarcinoma $(88 \%, 673 / 767)$ located in the distal esophagus or gastroesophageal junction $(91 \%, 696 / 767)$. Complete thoracic lymphadenectomy was accomplished in $82 \%$ of patients, and $18 \%$ of the population underwent transhiatal resection with lower thoracic and abdominal lymphadenectomy. Pathologic complete response was seen in 29\% (57/195) of patients receiving CXRT and 3\% (2/73) in patients receiving induction chemotherapy alone.

\section{Staging Accuracy}

Stage migration was evaluated among the 499 patients undergoing primary esophagectomy. The overall accuracy of staging was $14 \%$ (70/499). Clinical understaging was seen in 50\% (248/499) and overstaging in 36\% (181/499) of patients. A contemporary cohort (2008-2012) was analyzed separately, as the use and experience of EUS had changed over the study period. This subgroup demonstrated equivalent staging accuracy $(15 \%, 28 / 188)$ (Table 2). Pathologic nodal understaging $(\mathrm{pN}>0)$ was seen in 39\% (195/499) of patients, or 78\% (195/248) of all understaged patients. Overall T-status accuracy was $24 \%$ (118/499), with $32 \%$ (159/499) of patients being understaged (pT $>2)$ and $45 \%(222 / 499)$ patients being overstaged $(\mathrm{pT}<2)$ (Table 3). There were 133 patients with pT $<2$ and available data stratifying T1a and T1b;28\% (37/133) staged as T1aN0 and $56 \%(74 / 133)$ as T1bN0 (Table 4$)$ with the remaining $17 \%(22 / 133)$ of patients having pathologic nodal involvement $(\mathrm{pN}>0)$. 
TABLE 1. Demographic and clinical outcomes, grouped by preoperative treatment modality

\begin{tabular}{|c|c|c|c|c|}
\hline Variable & $\frac{\text { CXRT }}{\mathbf{N}=195(\%)}$ & $\frac{\text { Chemo }}{\mathrm{N}=73(\%)}$ & $\frac{\text { Surgery }}{\mathrm{N}=499(\%)}$ & $P$ value \\
\hline Age, y, median (range) & $62(19-94)$ & $63(22-78)$ & $66(21-93)$ & $<.001$ \\
\hline Sex & & & & .127 \\
\hline M & $165(85)$ & $60(82)$ & 389 (78) & \\
\hline $\mathrm{F}$ & $30(15)$ & $13(18)$ & $110(22)$ & \\
\hline Histology & & & & .115 \\
\hline Adenocarcinoma & $163(84)$ & $66(90)$ & $444(88)$ & \\
\hline Squamous cell & $32(16)$ & $7(10)$ & $94(12)$ & \\
\hline Location & & & & .638 \\
\hline Upper one-third & $2(1)$ & $0(0)$ & $7(1)$ & \\
\hline Middle one-third & $18(9)$ & $5(7)$ & $29(6)$ & \\
\hline Distal one-third & $102(52)$ & $45(62)$ & $271(55)$ & \\
\hline GEJ & $73(37)$ & $23(32)$ & $182(37)$ & \\
\hline Type of resection & & & & $<.001$ \\
\hline Right transthoracic (Ivor Lewis) & $72(37)$ & $21(29)$ & $170(34)$ & \\
\hline Transhiatal & $56(29)$ & $1(1)$ & $77(15)$ & \\
\hline Three-hole & $46(23)$ & $41(58)$ & $78(16)$ & \\
\hline Minimally invasive & $11(6)$ & $5(7)$ & $89(18)$ & \\
\hline Left transthoracic & $9(5)$ & $4(6)$ & $76(15)$ & \\
\hline N/A & $1(0.5)$ & $0(0)$ & $9(2)$ & \\
\hline EUS & & & & $<.001$ \\
\hline No & $60(31)$ & $41(56)$ & $70(14)$ & \\
\hline Yes & $125(64)$ & $27(37)$ & $225(45)$ & \\
\hline N/A & $10(5)$ & $5(7)$ & $204(41)$ & \\
\hline PET & & & & .005 \\
\hline No & $46(24)$ & $14(19)$ & $111(22)$ & \\
\hline Yes & $121(62)$ & $44(60)$ & $164(32)$ & \\
\hline N/A & $28(14)$ & $15(21)$ & $224(45)$ & \\
\hline Lymphovascular invasion (postop) & & & & $<.001$ \\
\hline No & $105(54)$ & $42(58)$ & $231(46)$ & \\
\hline Yes & $24(12)$ & $29(40)$ & $170(34)$ & \\
\hline N/A & $66(34)$ & $2(3)$ & $98(20)$ & \\
\hline Grade & & & & .564 \\
\hline Well & $8(4)$ & $1(1)$ & $46(9)$ & \\
\hline Moderate & $32(16)$ & $11(15)$ & $127(25)$ & \\
\hline Poorly & $28(14)$ & $11(15)$ & $134(27)$ & \\
\hline Undifferentiated & $2(1)$ & $1(1)$ & $5(1)$ & \\
\hline N/A & $125(64)$ & $49(67)$ & $314(63)$ & \\
\hline Pathologic T & [урT] & [урT] & {$[\mathrm{pT}]$} & \\
\hline T0 & $64(33)$ & $2(2)$ & $4(1)$ & \\
\hline Tis & $1(0.5)$ & $1(1)$ & $2(0.5)$ & \\
\hline $\mathrm{T} 1$ & $44(23)$ & $19(26)$ & $216(43)$ & \\
\hline $\mathrm{T} 2$ & $35(18)$ & $11(15)$ & $118(24)$ & \\
\hline $\mathrm{T} 3$ & $50(26)$ & $32(44)$ & $153(31)$ & \\
\hline $\mathrm{T} 4$ & $1(0.5)$ & $8(11)$ & $6(1)$ & \\
\hline Pathologic N & [урT] & [урT] & {$[\mathrm{pT}]$} & .001 \\
\hline No & $141(72)$ & $35(48)$ & $304(61)$ & \\
\hline$>\mathrm{N} 0$ & $54(28)$ & $38(52)$ & $195(39)$ & \\
\hline \multicolumn{5}{|l|}{ Lymph nodes } \\
\hline Mean no. & 18.1 & 22.5 & 21.9 & .002 \\
\hline Mean no. positive & 1 & 2.4 & 1.3 & $<.001$ \\
\hline Pathologic complete response & $57(29)$ & $2(3)$ & NA & \\
\hline
\end{tabular}


TABLE 1. Continued

\begin{tabular}{|c|c|c|c|c|}
\hline Variable & $\frac{\text { CXRT }}{\mathbf{N}=195(\%)}$ & $\frac{\text { Chemo }}{\mathrm{N}=73(\%)}$ & $\frac{\text { Surgery }}{\mathrm{N}=499(\%)}$ & $P$ value \\
\hline 90-day mortality* & & & $15(3)$ & .987 \\
\hline 30-day mortality* & & & $5(2)$ & .280 \\
\hline Anastomotic Leak* & & & $36(11.9)$ & .771 \\
\hline
\end{tabular}

$C X R T$, Chemoradiation; $M$, male; $F$, female; GEJ, gastroesophageal junction; $N / A$, not available; $E U S$, endoscopic ultrasound; PET, positron emission tomography. *Combined pretreatment groups (CXRT, chemo) vs primary esophagectomy.

\section{Selection Bias}

Individual practice patterns potentially introduce bias into stage migration and selection of therapy. A preference to administer induction therapy to perceived high-risk patients may exist at centers selectively using preoperative therapy compared with those who assign all patients with cT2N0 to receive induction treatment. To assess for selection bias based on the propensity of individual centers to use induction therapy, the 15 contributing centers were separated into 4 groups using a regression tree analysis based on the frequency of induction therapy (Figure E1). Primary esophagectomy was performed in (1) $100 \%$ (127/127), (2) 94\% (100/107), (3) 68\% (181/226), and (4) $34 \%(91 / 266)$ of patients in the 4 preference groups. Stage migration was then assessed for each practice pattern group in the primary esophagectomy cohort. Staging accuracy by center preferences was $20 \%(26 / 127), 15 \%(15 /$ $100), 13 \%(23 / 182)$, and $7 \%(6 / 91)$, in the 4 groups (1-4), respectively $(P=.03)$.

\section{Predictors of Advanced Disease}

Given the clinical-pathologic staging discordance, we sought to identify independent predictors of pathologic $\mathrm{N}>0$, and overall clinical under-staging ( $\mathrm{T}, \mathrm{N}$ status, or both). A regression tree analysis was performed in the primary esophagectomy cohort using preoperatively obtained tumor length (EGD or EUS measurement), identifying an optimal cut point of $3.25 \mathrm{~cm}$. The incidence of nodal disease $(\mathrm{N}>0)$ tended to increase with tumor length. For tumors $<3.25 \mathrm{~cm} \mathrm{33 \%}(77 / 232)$ of patients were node positive; when $>3.25 \mathrm{~cm}$, the incidence increased to $54 \%(63 / 117)$. For tumors $<2 \mathrm{~cm}$ in length, the incidence of nodal metastases was $24 \%$ (Table 5). When overall stage was evaluated the results were similar (Table 6). Multivariable logistic

TABLE 2. Overall pathologic stage migration for complete primary esophagectomy and modern cohort

\begin{tabular}{lcc}
\hline & Overall & $\frac{\mathbf{2 0 0 8 - 2 0 1 2}}{\mathbf{N}=\mathbf{1 8 8}(\%)}$ \\
\cline { 2 - 3 } Pathologic status & $\mathbf{N = \mathbf { 4 9 9 } ( \% )}$ & $28(15)$ \\
pT2N0 & $70(14)$ & $160(85)$ \\
Not pT2N0 & $429(86)$ & $89(47)$ \\
Understaged & $248(50)$ & $71(38)$ \\
Overstaged & $181(36)$ & \\
\hline
\end{tabular}

regression was performed to identify independent predictors of nodal upstaging after primary esophagectomy; tumor length $>3.25 \mathrm{~cm}$ independently predicted $\mathrm{pN}>0$ (odds ratio, 2.2; 95\% confidence interval, 1.2-4.0, $P<.001$ ) (Table 7). When the adenocarcinoma cohort was analyzed separately, the results were unchanged (Table 8). Similarly, when adjusting for clustering at the institutional level, there was no change in results (Table E1).

Recognizing that LVI is potentially evaluable preoperatively, an exploratory analysis was performed using postoperative, pathologically obtained variables including LVI and tumor length (when preoperative was unavailable). Preoperative length was compared with pathologic length to validate the use of these measurements, and no significant difference was identified (Figure E2). In a similar fashion, a regression tree analysis was performed, identifying an optimal tumor length cut-point of $3.5 \mathrm{~cm}$. The greatestrisk subgroup were patients with LVI and tumors $>3.5 \mathrm{~cm}$; in this subgroup, $92 \%$ (48/52) of patients had nodal involvement on final pathology (Table E2). In the primary esophagectomy group, LVI and tumor length $>3.5 \mathrm{~cm}$ independently predicted $\mathrm{pN}>0$ on multivariate model (Table E3).

\section{Survival Outcomes}

Median follow-up for all patients was 30 months at the time of analysis. Five-year overall survival for pathologic T2N0 patients undergoing primary esophagectomy was $57 \%$, with a median survival of 83 months (Figure 1, $A$ ). No difference was seen between pretreatment groups, with median overall survival of 71, 70, and 63 months for CXRT, chemotherapy, and primary esophagectomy, respectively $(P=.956)$ (Table 9 and Figure $1, B)$. When preoperatively treated patients (chemotherapy and CXRT) were combined and compared with the primary esophagectomy group, the results were unchanged. Multivariable Cox regression analysis of the entire cT2N0 cohort, including both pre- and postoperative variables identified age, tumor length, $\mathrm{pN}>0, \mathrm{pT}$, and $\mathrm{pM}$ as independent predictors of overall survival (Table 10). Analysis of the adenocarcinoma subgroup alone demonstrated similar results (Table 11). McKeown and minimally invasive techniques were associated with reduced overall survival; given the variability in the definition of "minimally invasive esophagectomy," 
TABLE 3. Overall T, N, M, pathologic stage breakdown, primary esophagectomy cohort

\begin{tabular}{cccr}
\hline \multicolumn{4}{c}{ Pathologic stage migration } \\
\hline & Not pT2N0 (\%) & pT2N0 (\%) & Total \\
\cline { 2 - 4 } & $\mathbf{N}=\mathbf{4 2 9}$ & & $\mathbf{N}=\mathbf{4 9 9}$ \\
\hline pT & & $0(0)$ & \\
T0 & $4(1)$ & $0(0)$ & 4 \\
Tis & $2(1)$ & $0(0)$ & 216 \\
T1 & $216(50)$ & $70(100)$ & 118 \\
T2 & $48(11)$ & $0(0)$ & 153 \\
T3 & $153(36)$ & $0(0)$ & 6 \\
T4 & $6(1)$ & & \\
pN & & $70(100)$ & 304 \\
N0 & $234(55)$ & $0(0)$ & 114 \\
N1 & $114(27)$ & $0(0)$ & 57 \\
N2 & $57(13)$ & $0(0)$ & 24 \\
N3 & $24(6)$ & & \\
pM & & $70(100)$ & 496 \\
M0 & $426(99)$ & $0(0)$ & 3 \\
M1 & $3(1)$ & & \\
\hline
\end{tabular}

further examination of this variable was not performed. When adjusted for clustering at the institutional level the Cox regression analysis, results were largely unchanged, although the outcomes favored chemotherapy alone over CXRT (Table E4).

In selected high-risk subgroups $(\mathrm{pN}>0, \mathrm{LVI}$, length $>3.5 \mathrm{~cm}$ ), there was no survival advantage for either induction chemotherapy or CXRT as compared with primary esophagectomy (Figure E3, A-D). In the greatest-risk cohort, those with primaries $>3.5 \mathrm{~cm}$ and LVI, outcomes were expectedly poor, with a median survival of 24 months (Table E5). Overall, preoperative therapy failed to demonstrate any survival benefit over primary esophagectomy in either the complete study cohort or the exploratory analysis high-risk subgroups.

\section{Clinical and Perioperative Outcomes}

Thirty- and ninety-day mortality was $1 \%(9 / 767)$ and $3 \%$ (23/767) for the entire cohort, respectively. It did not differ in the primary esophagectomy $(1 \% 4 / 499,3 \%, 15 / 499)$ versus the pretreatment $(2 \% 5 / 268,3 \%, 8 / 260)$ groups. Of 523 patients with available data, the incidence of anastomotic leak was also similar between the pretreatment and

TABLE 4. Pathologic T1 subgrouping, primary esophagectomy cohort

\begin{tabular}{lc}
\hline pT1 subgroup & $\mathbf{N}=\mathbf{1 3 3} *(\%)$ \\
\hline pT1aN0 & $37(28)$ \\
pT1bN0 & $74(56)$ \\
pT1aN1 & $4(3)$ \\
pT1bN1 & $18(14)$ \\
\hline *
\end{tabular}

*Subgroup of pT1 (133/222) with available data.
TABLE 5. Pathologic nodal stage migration based on preoperative tumor length, primary esophagectomy cohort

\begin{tabular}{lccc}
\hline & \multicolumn{3}{c}{ Tumor size } \\
\cline { 2 - 4 } pN status & $\frac{<\mathbf{2 ~ c m}}{\mathbf{N}=\mathbf{7 1}(\%)}$ & $\frac{<\mathbf{3 . 2 5} \mathbf{~ c m}}{\mathbf{N}=\mathbf{2 3 2}(\%)}$ & $\frac{>\mathbf{3 . 2 5} \mathbf{~ c m}}{\mathbf{N}=\mathbf{1 1 7}(\%)}$ \\
\hline $\mathrm{pN}=0$ & $54(76)$ & $154(67)$ & $54(46)$ \\
$\mathrm{pN}>0$ & $17(24)$ & $78(33)$ & $63(54)$ \\
\hline
\end{tabular}

primary esophagectomy groups $(11.9 \%$ vs $12 \%, P=.77)$ (Table 1).

\section{DISCUSSION}

The benefit of induction CXRT followed by surgery has been established for locally advanced esophageal carcinoma based on the outcomes of several randomized controlled trials. ${ }^{7-10}$ Unfortunately, we have yet to identify the clinical risk profile of specific patient cohorts who will derive benefit from this treatment paradigm. Clinical T2N0 esophageal cancer represents a poorly understood and heterogeneous patient group in which the benefits of trimodality therapy are unproven.

In our study, we found that within high-volume centers, the staging accuracy for cT2N0 esophageal cancer was poor and did not improve over time. With increased experience using modern modalities, including EUS, axial computed tomography, and PET, staging inaccuracy remained problematic. This is consistent with recent publications analyzing data from the Society of Thoracic Surgeons database, the National Cancer Database, and smaller singleinstitution series. ${ }^{2,5,6,11,12}$ The likelihood of either over- or understaging is nearly equivalent when the primary esophagectomy cohort is evaluated. Recognizing that identifying predictors of staging inaccuracies, targeting high- and low-risk patients, could alter the treatment recommendations offered, we focused our analysis on potentially evaluable pretreatment variables. In our study, multivariable modeling identified primary tumor length $>3.25 \mathrm{~cm}$ as a significant predictor of nodal involvement. When postoperatively obtained variables were included, the presence of LVI significantly increased the likelihood of nodal disease. As would be expected, these same factors were associated with a diminished overall survival across all treatment groups. This finding is consistent with previously

TABLE 6. Overall pathologic stage migration based on preoperative tumor length, primary esophagectomy cohort

\begin{tabular}{lcc}
\hline & \multicolumn{2}{c}{ Tumor size* } \\
\cline { 2 - 3 } Final pathology & $\frac{<\mathbf{3 . 2 5} \mathbf{~ c m}}{\mathbf{N}=\mathbf{2 3 2}(\%)}$ & $\frac{>\mathbf{3 . 2 5} \mathbf{~ c m}}{\mathbf{N}=\mathbf{1 1 7}(\%)}$ \\
\hline >pT2N0 & $105(45)$ & $74(63)$ \\
pT2N0 & $37(16)$ & $17(15)$ \\
$<$ pT2N0 $\dagger$ & $90(39)$ & $26(22)$ \\
\hline *Preoperative. $\dagger$ pT0-1N0. & &
\end{tabular}

*Preoperative. $\nmid \mathrm{pT} 0-1 \mathrm{~N} 0$. 
TABLE 7. Predictors of $\mathrm{pN}>0$

\begin{tabular}{|c|c|c|c|c|}
\hline \multirow[b]{2}{*}{ Variable } & \multicolumn{2}{|c|}{ Univariable } & \multicolumn{2}{|c|}{ Multivariable } \\
\hline & OR (CI) & $P$ value & OR (CI) & $P$ value \\
\hline Age & $1(0.985-1.016)$ & .943 & $1(0.978-1.018)$ & .82 \\
\hline Histology & & .31 & & .938 \\
\hline Adenocarcinoma & 1 & & 1 & \\
\hline Squamous & $0.73(0.0405-1.330)$ & & $1.03(0.476-2.236)$ & \\
\hline Location & & .147 & & .140 \\
\hline Upper-middle one-third & 1 & & 1 & \\
\hline Lower one-third-GEJ & $1.75(0.822-3.708)$ & & $2.033(0.792-5.22)$ & \\
\hline Sex & & .27 & & .474 \\
\hline M & 1 & & 1 & \\
\hline $\mathrm{F}$ & $0.78(0.501-1.214)$ & & $0.812(0.460-1.434)$ & \\
\hline Length & & $<.001$ & & $<.001$ \\
\hline$<3.25 \mathrm{~cm}$ & 1 & & 1 & \\
\hline$\geq 3.25 \mathrm{~cm}$ & $3.17(2.091-4.804)$ & & $2.34(1.482-3.697)$ & \\
\hline
\end{tabular}

$O R$, Odds ratio; $C I$, confidence interval; $G E J$, gastroesophageal junction; $M$, male; $F$, female.

published data identifying tumor length $>2 \mathrm{~cm}$ and LVI as markers for increased risk of nodal metastases. ${ }^{4,13,14}$ This would suggest that adequate pretreatment tissue evaluation may allow for accurate predictions regarding the likelihood of nodal upstaging on final pathology. With regard to histologic grade, our volume of data was limited and failed to show an independent correlation to staging, although this has been demonstrated in prior series. ${ }^{15,16}$ Consistent with the addition of histologic grade to the seventh edition American Joint Committee on Cancer/ Union for International Cancer Control stage groupings for esophageal cancer, our findings suggest that outcomes rely on a more than simple tumor, node, and metastases status. ${ }^{17}$ Our data suggest that endoscopic intervention in the context of improving lesion characterization (grade, LVI) may play an important role in patients with cT2N0 esophageal cancer. When appropriate, endoscopic resection provides pathologic T-status, assessment of tumor grade, and identification of LVI, allowing for an enhanced

TABLE 8. Predictors of $\mathbf{p N}>\mathbf{0}$ (adenocarcinoma only)

\begin{tabular}{lcc}
\hline \multirow{2}{*}{ Variable } & \multicolumn{2}{c}{ Multivariable regression } \\
\cline { 2 - 3 } OR $($ CI $)$ & $\boldsymbol{P}$ value \\
\hline Age & $0.993(0.973-1.014)$ & .514 \\
Location & & .805 \\
$\quad$ Upper-middle one-third & 1 & \\
$\quad$ Lower one-third-GEJ & $1.165(0.347-3.911)$ & \\
Sex & & .345 \\
$\quad$ M & 1 & \\
F & $0.74(0.396-1.383)$ & \\
Length & & \\
$\quad<3.25 \mathrm{~cm}$ & 1 & \\
$\geq 3.25 \mathrm{~cm}$ & $2.386(1.476-3.857)$ & \\
\hline
\end{tabular}

$O R$, Odds ratio; $C I$, confidence interval; $G E J$, gastroesophageal junction; $M$, male; $F$, female. evaluation of risk for local-regionally advanced disease. In addition, many patients may be definitively treated with endoscopic therapy, avoiding esophagectomy completely. We have found this very useful in patients with tumors that are less than or equal to $2 \mathrm{~cm}$, noncircumferential, and with low fluorodeoxyglucose avidity. ${ }^{13,14,18}$ In contrast, identification of high-risk features (LVI, length $>3.25 \mathrm{~cm}$ ) allows for a more informed decision when deciding whether to pursue preoperative therapy and reduces the risk of undertreatment.

Treatment selection for patient with cT2N0 esophageal adenocarcinoma varies significantly worldwide. A review of the Society of Thoracic Surgeons database demonstrated that of the patients undergoing esophagectomy, $36 \%$ of them received some form of preoperative therapy. In a large European series, the use was essentially halved, with $19 \%$ of patients receiving induction therapy. ${ }^{2,19}$ Given the heterogeneity of treatment for this population, studies to date have not consistently demonstrated a benefit to induction therapy with respect to overall survival in unselected groups. The decision on whether to pursue induction therapy rests on the likelihood of a patient having more advanced disease than identified on clinical staging. The results of the ChemoRadiotherapy for Oesophageal cancer followed by Surgery Study (CROSS) trial $^{8,9}$ would suggest that the use of preoperative CXRT would result in an improvement in overall and progression-free survival in this group, given the likely degree of understaging. In a review of the National Cancer Database cT2N0 tumors, patients who were upstaged on final pathology had worse survival as compared with all patients receiving induction therapy, regardless of the final pathologic stage. ${ }^{15}$ Alternatively, the outcomes from the FFCD 9901 randomized study would suggest not only is there no survival benefit to neoadjuvant CXRT in early stage 


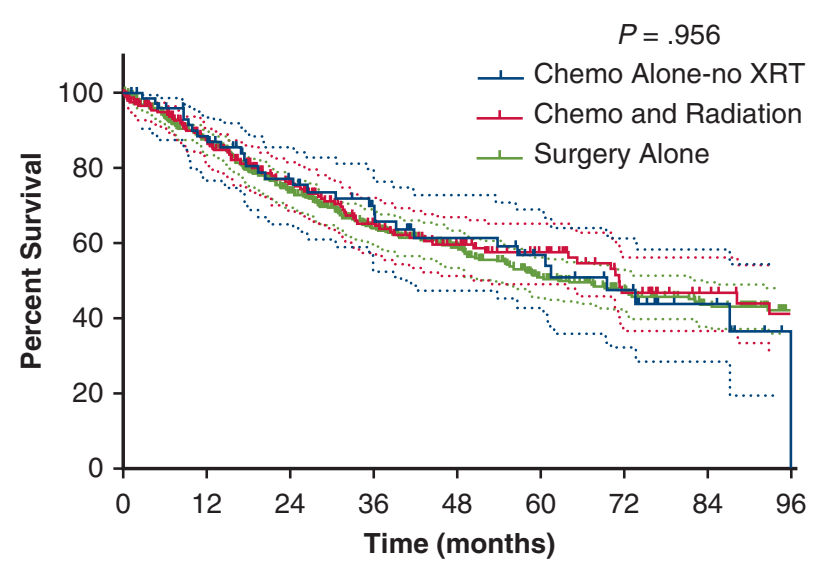

Number at Risk:

$\begin{array}{cccccccccc} & 499 & 283 & 155 & 85 & 40 & 16 & 4 & 1 & 0 \\ & 73 & 45 & 27 & 14 & 1 & 0 & & & \end{array}$

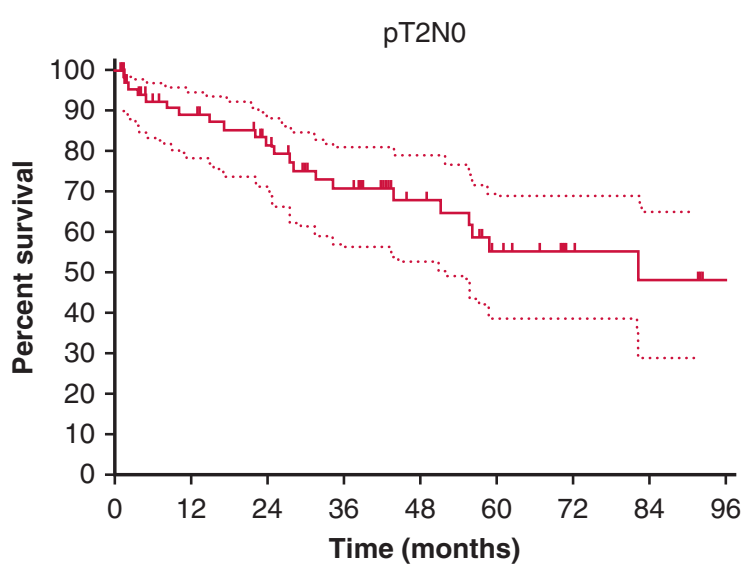

Number at Risk:

$\begin{array}{lllllllll}70 & 52 & 42 & 32 & 23 & 15 & 9 & 7 & 5\end{array}$

B

FIGURE 1. Kaplan-Meir survival estimates: (A) Overall survival for pT2N0, surgery-only group and (B) overall survival for cT2N0 patients undergoing esophagectomy, comparing induction chemotherapy, chemoradiation, and primary esophagectomy. XRT, Radiation.

(T1/2N0/+, T3N0) disease, but it may lead to an increased risk of peri-operative morbidity/mortality. ${ }^{20}$ Because the CROSS trial included patients with cT2N0, it would be interesting to identify if the overall survival benefit specifically failed extend to the cT2N0 subgroup and if the perioperative outcomes indeed worse. Alternatively, appropriate identification of patients most likely to be understaged offers the best opportunity for improved outcomes with the addition of preoperative therapy. The caveat to the use of LVI as a predictor for nodal involvement is that in our study this variable was identified on final pathology, making it a potential but not validated marker of understaging. Similar to previously published studies in our cohort, there did not appear to be a comparative survival advantage with the addition of preoperative chemotherapy or CXRT for unselected cT2N0 esophageal carcinoma. ${ }^{2,6,15}$ When we stratified for greater-risk subgroups, the results were largely unchanged, with no significant difference identified in any subgroup.

These results reflect the outcomes of an international group of focused esophageal centers, ideally eliminating some of the bias associated with review of large national databases, where practice consistency and surgical outcome quality control are limited. In addition, in an attempt to identify bias associated with the practice patterns of each individual center, staging accuracy was assessed by the percentage of patients who underwent induction therapy of any kind. This aided in identifying potential bias toward pretreatment of patients with greater-risk features in centers preferentially, although not exclusively, using primary esophagectomy.

Inherent selection bias limits the granularity of any outcome data, and some data were not reasonably attainable from all of the centers. In addition, predictive models of nodal upstaging included LVI, which in our series was based on identification on final pathology, and thus not a validated preoperatively evaluable variable. Longitudinal tumor length represented a predictor of outcomes, but given that preoperative measurements were not available on all patients, length on final pathology was included when required in a subgroup analysis. Access and preference for EUS and PET use varied by center, such that the staging was not truly uniform in the study cohort. Lastly, our dataset did not include cT2N0 patients who did not undergo esophagectomy either secondary to disease progression or complications related to induction therapy. This may favorably bias the results of the induction therapy groups as patients who did not tolerate induction therapy such

TABLE 9. Median survival estimates

\begin{tabular}{|c|c|c|c|c|c|}
\hline & \multicolumn{3}{|c|}{ Pretreatment group } & \multirow[b]{2}{*}{ Overall } & \multirow[b]{2}{*}{$P$ value } \\
\hline & CXRT & Chemo & Surgery alone & & \\
\hline Overall survival (all) & $71(53-90)$ & $70(50-89)$ & $63(48-78)$ & $69(58-81)$ & .956 \\
\hline RFS (all) & $53(35-71)$ & $70(41-99)$ & $51(37-65)$ & $53(35-71)$ & .795 \\
\hline pT2N0 & - & - & $82(62-102)$ & - & - \\
\hline
\end{tabular}

Values are months $(95 \% \mathrm{CI}) . C X R T$, Chemoradiation; $R F S$, recurrence-free survival. $* P$ value for CXRT vs surgery alone, chemo excluded. 
TABLE 10. Predictors of mortality

\begin{tabular}{|c|c|c|c|c|}
\hline \multirow[b]{2}{*}{ Variable } & \multicolumn{2}{|c|}{ Univariable } & \multicolumn{2}{|c|}{ Multivariable } \\
\hline & HR (CI) & $P$ value & HR (CI) & $P$ value \\
\hline Age & $1.03(1.02-1.04)$ & $<.001$ & $1.03(1.01-1.04)$ & $<.001$ \\
\hline (y)pT & & $<.001$ & & \\
\hline T0-Tis & 1 & & 1 & \\
\hline $\mathrm{T} 1$ & $0.85(0.53-1.38)$ & & $0.86(0.47-1.57)$ & \\
\hline $\mathrm{T} 2$ & $1.38(0.85-2.25)$ & & $1.21(0.66-2.22)$ & \\
\hline $\mathrm{T} 3$ & $2.9(1.85-4.60)$ & & $2.14(1.20-3.83)$ & \\
\hline $\mathrm{T} 4$ & $6.57(3.24-13.3)$ & & $4.49(1.95-10.4)$ & \\
\hline (y)pN & & $<.001$ & & $<.001$ \\
\hline No & 1 & & 1 & \\
\hline N1 & $2.11(1.60-2.80)$ & & $1.53(1.07-2.19)$ & \\
\hline $\mathrm{N} 2$ & $3.74(2.78-5.03)$ & & $2.48(1.65-3.72)$ & \\
\hline $\mathrm{N} 3$ & $5.82(3.86-8.80)$ & & $3.98(2.34-6.78)$ & \\
\hline (y)pM & & $<.001$ & & $<.001$ \\
\hline M0 & 1 & & 1 & \\
\hline M1 & $11.4(4.62-28.2)$ & & $6.12(2.30-16.3)$ & \\
\hline Histology & & .193 & & .033 \\
\hline Adenocarcinoma & 1 & & 1 & \\
\hline Squamous & $1.24(0.89-1.70)$ & & $1.61(1.04-2.48)$ & \\
\hline Location & & .504 & & .48 \\
\hline Upper-middle one-third & 1 & & 1 & \\
\hline Lower one third-GEJ & $1.15(0.76-1.70)$ & & $1.21(0.71-2.08)$ & \\
\hline Type of resection & & .01 & & .015 \\
\hline Right transthoracic & 1 & & 1 & \\
\hline Transhiatal & $1.35(0.97-1.89)$ & .077 & $1.21(0.79-1.83)$ & \\
\hline McKeown & $1.51(1.23-2.02)$ & .005 & $1.36(0.95-1.95)$ & \\
\hline MIE & $1.32(0.90-1.94)$ & .15 & $1.68(1.07-2.64)$ & \\
\hline Left transthoracic & $0.76(0.57-1.15)$ & .192 & $0.61(0.35-1.05)$ & \\
\hline N/A & $0.97(0.56-2.60)$ & .957 & $1.58(0.38-6.59)$ & \\
\hline Preoperative treatment & & .956 & & .071 \\
\hline CXRT & 1 & & 1 & \\
\hline Chemo alone & $1.03(0.68-1.57)$ & .879 & $0.56(0.34-0.92)$ & \\
\hline No treatment & $1.04(0.80-1.36)$ & .764 & $0.82(0.57-1.19)$ & \\
\hline Length & $1.07(1.02-1.13)$ & .84 & $1.01(0.94-1.07)$ & .004 \\
\hline Sex & & .561 & & .696 \\
\hline M & 1 & & 1 & \\
\hline F & $0.92(0.70-1.22)$ & & $1.07(0.75-1.54)$ & \\
\hline
\end{tabular}

HR, Hazard ratio; $C I$, confidence interval; GEJ, gastroesophageal junction; $M I E$, minimally invasive esophagectomy; N/A, not available; $C X R T$, chemoradiation; $M$, male; $F$, female.

that they were deemed unfit for esophagectomy or those who progressed or were identified to have advanced disease on restaging prior to undergoing resection were excluded.

\section{CONCLUSIONS}

The current accuracy of pathologic staging for patients with cT2N0 esophageal cancer remains poor, with an overall clinical to pathologic staging concordance of $14 \%$ in our series. This is consistent with both single-institution series as well as recent national database publications. Despite the heterogeneity of this group, the overall outcomes for patients did not differ based on a treatment strategy of either primary esophagectomy or esophagectomy after induction therapy. We were able to identify high- and low-risk groups for nodal disease based on attributable data obtained before assigning therapy. Tumor length $>3.25 \mathrm{~cm}$ predicted upstaging, either via pathologic node positivity or $\mathrm{pT}>2$. Conversely, $36 \%$ of patients undergoing primary esophagectomy staged as $<\mathrm{pT} 2 \mathrm{NO}$, many of whom could have undergone curative endoscopic resection for localized early stage disease. In centers that treat all patients with cT2N0 with trimodality therapy, this would represent a radical overtreatment in many cases. Given the overall absence of benefit to preoperative therapy, whether chemotherapy or CXRT, better patient selection is essential to improving outcomes. Endoscopic resection represents a potentially 
TABLE 11. Predictors of mortality (adenocarcinoma only)

\begin{tabular}{|c|c|c|}
\hline \multirow[b]{2}{*}{ Variable } & \multicolumn{2}{|c|}{ Multivariable } \\
\hline & HR (CI) & $P$ Value \\
\hline Age & $1.031(1.02-1.05)$ & $<.001$ \\
\hline pT & & $<.001$ \\
\hline T0-Tis & 1 & \\
\hline $\mathrm{T} 1$ & $0.61(0.33-1.13)$ & \\
\hline $\mathrm{T} 2$ & $0.76(0.41-1.46)$ & \\
\hline T3 & $1.31(0.71-2.40)$ & \\
\hline $\mathrm{T} 4$ & $2.67(1.11-6.42)$ & \\
\hline $\mathrm{pN}$ & & $<.001$ \\
\hline No & 1 & \\
\hline N1 & $1.61(1.09-2.38)$ & \\
\hline N2 & $2.70(1.74-4.19)$ & \\
\hline N3 & $3.86(2.21-6.65)$ & \\
\hline $\mathrm{pM}$ & & $<.001$ \\
\hline M0 & 1 & \\
\hline M1 & $10.7(3.92-29.1)$ & \\
\hline Location & & .48 \\
\hline Upper-middle one-third & 1 & \\
\hline Lower one-third-GEJ & $1.35(0.58-3.10)$ & \\
\hline Type of resection & & .009 \\
\hline Right transthoracic & 1 & \\
\hline Transhiatal & $1.44(0.93-2.25)$ & \\
\hline McKeown & $1.46(0.98-2.16)$ & \\
\hline Minimally invasive & $1.86(1.16-2.99)$ & \\
\hline Left transthoracic & $0.65(0.36-1.16)$ & \\
\hline N/A & $1.79(0.43-7.43)$ & \\
\hline Preoperative treatment & & .989 \\
\hline No treatment & 1 & \\
\hline CXRT/chemo & $1.002(0.71-1.42)$ & \\
\hline Length & $1.01(0.95-1.08)$ & .676 \\
\hline Sex & & .991 \\
\hline M & 1 & \\
\hline $\mathrm{F}$ & $0.998(0.65-1.53)$ & \\
\hline
\end{tabular}

$H R$, Hazard ratio; $C I$, confidence interval; $G E J$, gastroesophageal junction; $N / A$, not available; $C X R T$, chemoradiation; $M$, male; $F$, female.

valuable tool for early-stage esophageal cancer either as a diagnostic or therapeutic modality and warrants further investigation for application in selected patients with cT2N0 esophageal carcinoma.

\section{Conflict of Interest Statement}

Dr Shanda Blackmon holds a patent for an esophageal anastomotic device through Mayo Clinic Ventures. All other authors have nothing to disclose with regard to commercial support.

\section{References}

1. Crabtree TD, Yacoub WN, Puri V, Azar R, Zoole JB, Patterson GA, et al. Endoscopic ultrasound for early stage esophageal adenocarcinoma: implications for staging and survival. Ann Thorac Surg. 2011;91:1509-15; discussion 1515-6.

2. Crabtree TD, Kosinski AS, Puri V, Burfeind W, Bharat A, Patterson GA, et al. Evaluation of the reliability of clinical staging of T2 N0 esophageal cancer: a re- view of the Society of Thoracic Surgeons database. Ann Thorac Surg. 2013;96: 382-90.

3. Stiles BM, Mirza F, Coppolino A, Port JL, Lee PC, Paul S, et al. Clinical T2 T3N0M0 esophageal cancer: the risk of node positive disease. Ann Thorac Surg. 2011;92:491-6; discussion 496-8.

4. Gaur P, Sepesi B, Hofstetter WL, Correa AM, Bhutani MS, Vaporciyan AA, et al. A clinical nomogram predicting pathologic lymph node involvement in esophageal cancer patients. Ann Surg. 2010;252:611-7.

5. Zhang JQ, Hooker CM, Brock MV, Shin J, Lee S, How R, et al. Neoadjuvant chemoradiation therapy is beneficial for clinical stage T2 N0 esophageal cancer patients due to inaccurate preoperative staging. Ann Thorac Surg. 2012;93:429-35; discussion 436-7.

6. Speicher PJ, Ganapathi AM, Englum BR, Hartwig MG, Onaitis MW, D'Amico TA, et al. Induction therapy does not improve survival for clinical stage T2N0 esophageal cancer. J Thorac Oncol. 2014;9:1195-201.

7. Walsh TN, Noonan H, Hollywood D, Kelly A, Keeling N, Hennessy TP, et al. A comparison of multimodal therapy and surgery for esophageal adenocarcinoma. N Engl J Med. 1996;335:462-7.

8. Shapiro J, van Lanschot JJB, Hulshof MCCM, van Hagne P, van Berge Henegouwen MI, Wijnhoven BPL, et al. Neoadjuvant chemoradiotherapy plus surgery versus surgery alone for oesophageal or junctional cancer (CROSS): long-term results of a randomised controlled trial. Lancet Oncol. 2015;16: 1090-8.

9. van Hagen $\mathrm{P}$, Hulshof $\mathrm{MC}$, van Lanschot JJ, Steyerberg WE, van Bere Henegouwen MI, Wijnhovern BP, et al. Preoperative chemoradiotherapy for esophageal or junctional cancer. $N$ Engl J Med. 2012;366: 2074-84.

10. Tepper J, Krasna MJ, Niedzwiecki D, Hollis D, Reed CE, Goldberg R, et al. Phase III trial of trimodality therapy with cisplatin, fluorouracil, radiotherapy, and surgery compared with surgery alone for esophageal cancer: CALGB 9781. J Clin Oncol. 2008;26:1086-92.

11. Rice TW, Mason DP, Murthy SC, Zuccaro G Jr, Adelstein DJ, Rybicki LA, et al. T2NOM0 esophageal cancer. J Thorac Cardiovasc Surg. 2007;133:317-24.

12. Hardacker TJ, Ceppa D, Okereke I, Rieger KM, Jalal SI, LeBlanc JK, et al. Treatment of clinical T2NOM0 esophageal cancer. Ann Surg Oncol. 2014;21: 3739-43.

13. Gaur P, Sepesi B, Hofstetter WL, Correa AM, Bhutani MS, Watson TJ, et al. Endoscopic esophageal tumor length: a prognostic factor for patients with esophageal cancer. Cancer. 2011;117:63-9.

14. Yendamuri S, Swisher SG, Correa AM, Hofstetter W, Ajani JA, Francis A, et al. Esophageal tumor length is independently associated with long-term survival. Cancer. 2009;115:508-16.

15. Samson P, Puri V, Robinson C, Lockhart C, Carpenter D, Broderick S, et al. Clinical T2NO esophageal cancer: identifying pretreatment characteristics associated with pathologic upstaging and the potential role for induction therapy. Ann Thorac Surg. 2016;101:2102-11.

16. Dikken JL, Colt DG, Klimstra DS, Rizk NP, van Grieken N, ilson D, et al. Prospective impact of tumor grade assessment in biopsies on tumor stage and prognostic grouping in gastroesophageal adenocarcinoma: relevance of the seventh edition American joint committee on cancer staging manual revision. Cancer. 2012;118:349-57.

17. Rice TW, Rusch VW, Ishwaran H, Blackston EH, Worldwide Esophageal Cancer Collaboration. Cancer of the esophagus and esophagogastric junction: datadriven staging for the seventh edition of the American joint committee on cancer/international union against cancer cancer staging manuals. Cancer. 2010; 116:3763-73.

18. Dhupar R, Rice RD, Correa AM, Weston BR, Bhutani MS, Maru DM, et al. Endoscopic ultrasound estimated for tumor depth at the gastroesophageal junction are inaccurate: implications for the liberal use of endoscopic resection. Ann Thorac Surg. 2015;100:1812-6.

19. Markar SR, Gronnier C, Pasquer A, Duhamel A, Beal H, Thereaux J, et al. Role of neoadjuvant treatment in clinical T2N0M0 oesophageal cancer: results from a retrospective multi-center European study. Eur J Cancer. 2016;56:59-68.

20. Mariette C, Dahan L, Mornex F, Maillard E, Thomas PA, Meunier B, et al. Surgery alone versus chemoradiotherapy followed by surgery for stage I and II esophgeal cancer: final analysis of randomized contrlled phase III FFCD 9901. J Clin Oncol. 2014;32:2416-22.

Key Words: esophageal cancer, neoadjuvant therapy, staging, endoscopic therapy 
APPENDIX 1. Complete list of authors, contributing, and current institutions

\begin{tabular}{|c|c|c|}
\hline Site & Principal investigator & Current institution \\
\hline MD Anderson Cancer Center, Houston, Tex* & $\begin{array}{l}\text { Scott M. Atay, MD, }{ }^{1} \text { Arlene Correa PhD, } \\
\text { Wayne L. Hofstetter MD, Stephen G. } \\
\text { Swisher, MD, Jaffer Ajani, MD }\end{array}$ & $\begin{array}{l}{ }^{1} \text { University of Southern California, Los } \\
\text { Angeles, California }\end{array}$ \\
\hline $\begin{array}{l}\text { New York-Presbyterian/Weill Cornell } \\
\text { Medical Center, New York, NY** }\end{array}$ & Nassar K. Altorki, MD & \\
\hline Mayo Clinic, Rochester, Minn & Shanda H. Blackmon, MD & \\
\hline $\begin{array}{l}\text { Cleveland Clinic Foundation, Cleveland, } \\
\text { Ohio }\end{array}$ & $\begin{array}{l}\text { Eugene H. Blackstone, MD, Thomas W. } \\
\text { Rice, MD }\end{array}$ & \\
\hline Washington University, St Louis, Miss & Traves D. Crabtree, MD* & $\begin{array}{l}\text { Southern Illinois University, Springfield, } \\
\text { Illinois }\end{array}$ \\
\hline $\begin{array}{l}\text { Duke University Medical Center, Durham, } \\
\text { NC }\end{array}$ & Thomas A. D'Amico, MD & \\
\hline University of Toronto, Toronto, Canada* & Gail E. Darling, MD & \\
\hline $\begin{array}{l}\text { University of Southern California, Los } \\
\text { Angeles, Calif* }\end{array}$ & $\begin{array}{l}\text { Steven R. DeMeester, MD, }{ }^{1} \text { Thomas R. } \\
\text { DeMeester, MD, Stephanie G. Worrell, } \\
\text { MD }^{2}\end{array}$ & $\begin{array}{l}{ }^{1} \text { The Oregon Clinic, Portland, Ore; } \\
{ }^{2} \text { University of Michigan, Ann Arbor, Mich }\end{array}$ \\
\hline McGill University, Montreal, Canada* & Lorenzo E. Ferri, MD, PhD & \\
\hline Harvard Medical School, Boston, Mass & Henning A. Gaissert, MD & \\
\hline $\begin{array}{l}\text { Jersey Shore University Medical Center, } \\
\text { Neptune, NJ }\end{array}$ & Mark J. Krasna, MD & \\
\hline University Hospital, Leuven, Belgium* & $\begin{array}{l}\text { Antoon Lerut, MD, PhD, Phillippe Nafteux, } \\
\text { MD, PhD, Johnny Moons, RN, MScN }\end{array}$ & \\
\hline University of Arizona, Tucson, Ariz & Alex G. Little, MD & \\
\hline $\begin{array}{l}\text { Virginia Mason Medical Center, Seattle, } \\
\text { Wash* }\end{array}$ & $\begin{array}{l}\text { Donald E. Low, MD, Phillip W. Carrott, MD, } \\
\text { Henner M. Schmidt, MD }\end{array}$ & $\begin{array}{l}{ }^{1} \text { University Hospital Zurich, Zurich, } \\
\text { Switzerland }\end{array}$ \\
\hline WellStar Healthcare, Ga & Daniel Miller, MD & \\
\hline $\begin{array}{l}\text { University of Pittsburgh Medical Center, } \\
\text { Pittsburgh, } \mathrm{Pa}^{*}\end{array}$ & Katie S. Nason, MD, James D. Luketich, MD & \\
\hline University of Michigan, Ann Arbor, Mich* & $\begin{array}{l}\text { Mark B. Orringer, MD, Andrew C. Chang, } \\
\text { MD }\end{array}$ & \\
\hline $\begin{array}{l}\text { Memorial Sloan Kettering Cancer Center, } \\
\text { New York, } \mathrm{NY}^{*}\end{array}$ & Nabil P. Rizk, $\mathrm{MD}^{1}$ & $\begin{array}{l}{ }^{1} \text { Hackensack University Medical Center, } \\
\text { Hackensack, New Jersey }\end{array}$ \\
\hline University of Helsinki, Helsinki, Finland* & Jarmo A. Salo, MD & \\
\hline University Hospital, Zurich, Switzerland & Paul M. Schneider, MD & \\
\hline $\begin{array}{l}\text { University of Queensland, Brisbane, } \\
\text { Australia* }\end{array}$ & Bernard Mark Smithers, MBBS & \\
\hline $\begin{array}{l}\text { University of Dusseldorf, Dusseldorf, } \\
\text { Germany* }\end{array}$ & Daniel Vallböhmer, MD & \\
\hline $\begin{array}{l}\text { Erasmus Medical Center Rotterdam, } \\
\text { Rotterdam, Netherlands* }\end{array}$ & J. J. van Lanschot, $\mathrm{MD}, \mathrm{PhD}$ & \\
\hline University of Washington, Seattle, Wash* & Thomas K. Varghese, MD, MS ${ }^{1}$ & ${ }^{1}$ University of Utah, Salt Lake City, Utah \\
\hline University of Rochester, Rochester, NY & Thomas J. Watson, MD, ${ }^{1}$ Jeff H. Peters, MD $^{2}$ & $\begin{array}{l}{ }^{1} \text { Medstar Health, Washington, DC; } \\
{ }^{2} \text { University Hospitals, Cleveland, Ohio }\end{array}$ \\
\hline $\begin{array}{l}\text { Johns Hopkins Medical Institutions, } \\
\text { Baltimore, Md }\end{array}$ & Stephen C. Yang, MD & \\
\hline
\end{tabular}

*Centers contributing patient data. 


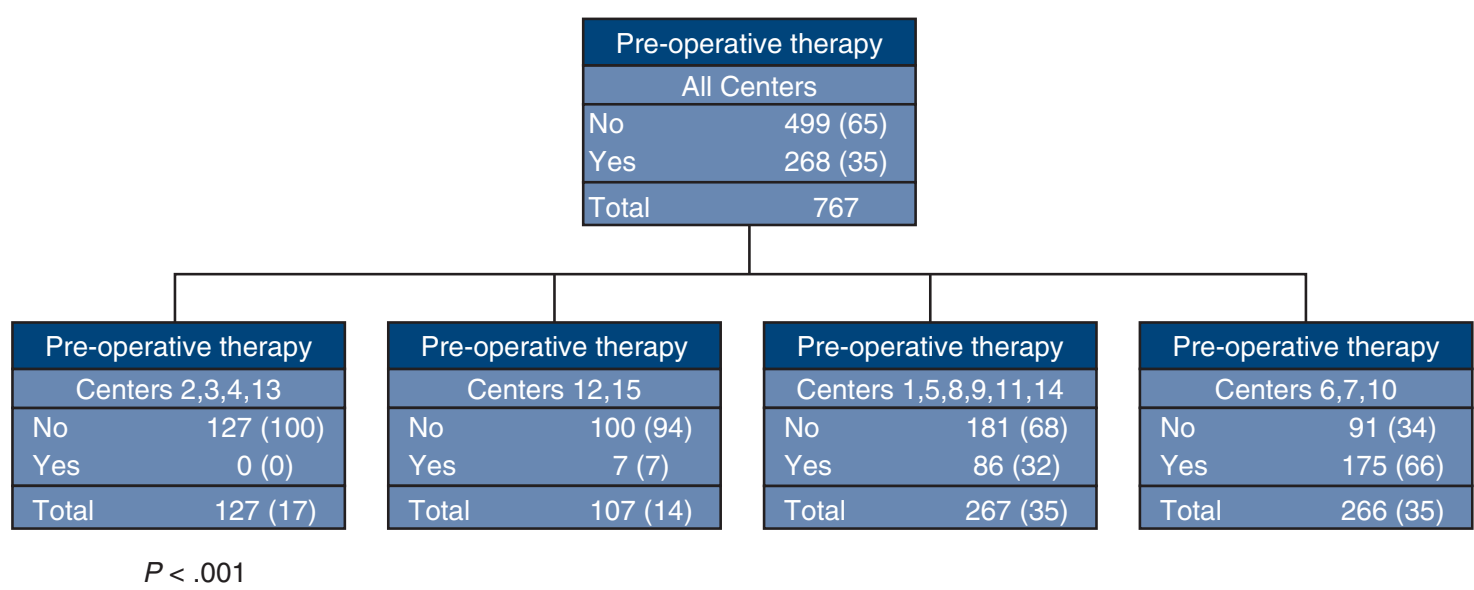

FIGURE E1. Regression tree analysis predictive of center preferences for the use of neoadjuvant chemotherapy $(P<.001)$.

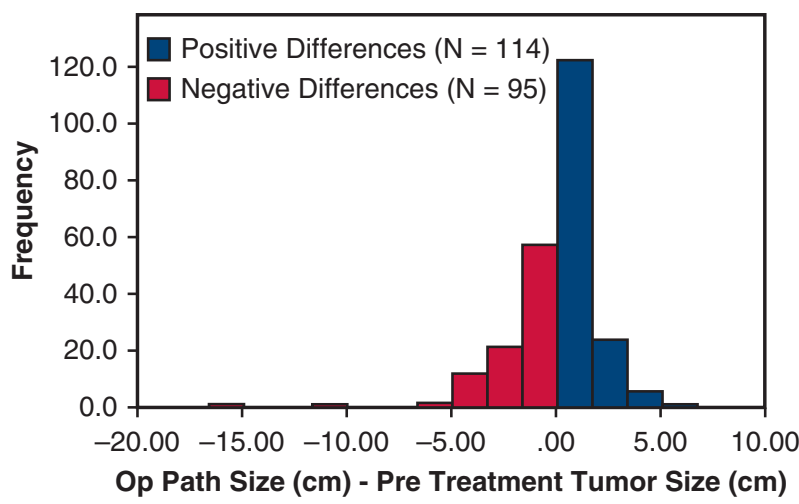

FIGURE E2. Differences between operative (pathologic) and preoperative (when available) tumor length $(P=.514)$. 


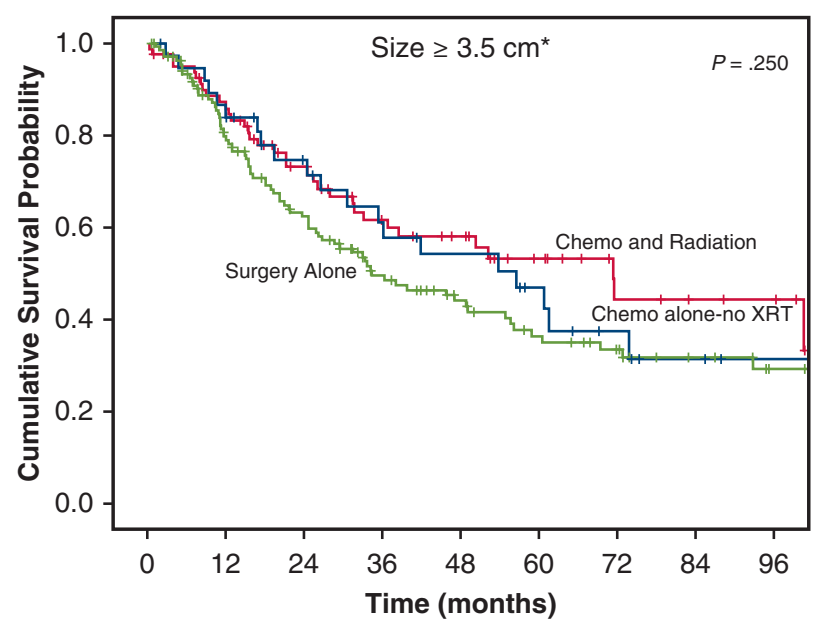

Number at Risk:

$\begin{array}{ccccccccc}146 & 99 & 73 & 49 & 36 & 27 & 21 & 15 & 8 \\ 38 & 31 & 23 & 18 & 15 & 10 & 6 & 3 & 1 \\ 83 & 65 & 47 & 35 & 27 & 17 & 10 & 8 & 7\end{array}$

A

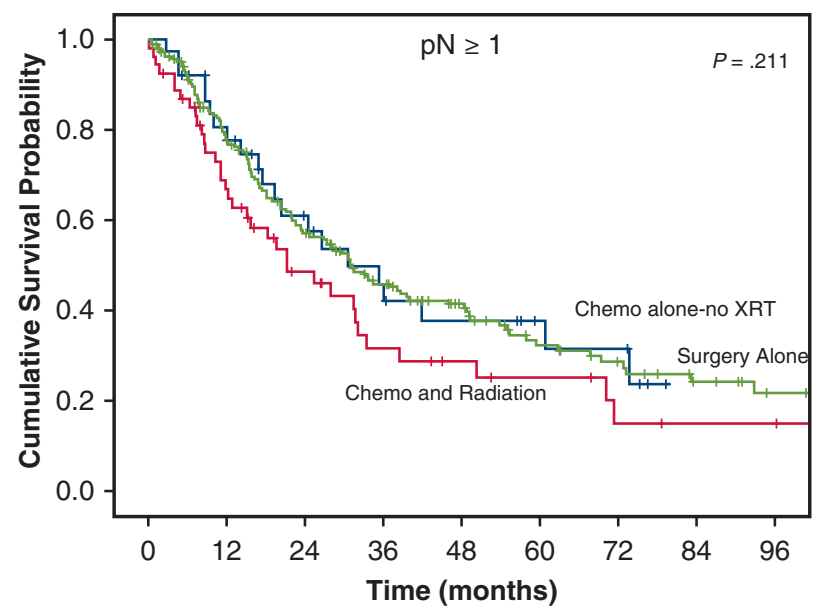

Number at Risk:

$\begin{array}{ccccccccc}195 & 134 & 95 & 67 & 45 & 29 & 21 & 14 & 7 \\ 38 & 27 & 17 & 12 & 9 & 6 & 5 & 0 & \\ 54 & 33 & 19 & 11 & 8 & 6 & 3 & 2 & 2\end{array}$

C

FIGURE E3. A-D, Kaplan-Meir survival estimates for selected high-risk subgroups of the surgery only cohort comparing all 3 pretreatment groups: (A) size $>3.5 \mathrm{~cm}$, (B) LVI, (C) pN1, (D) size $>3.5 \mathrm{~cm}$ and LVI. $* P=.74$. Comparison of primary esophagectomy vs chemoradiation only. Median and 5 -year survival estimates listed in Table E4. LVI, Lymphovascular invasion; XRT, radiation.

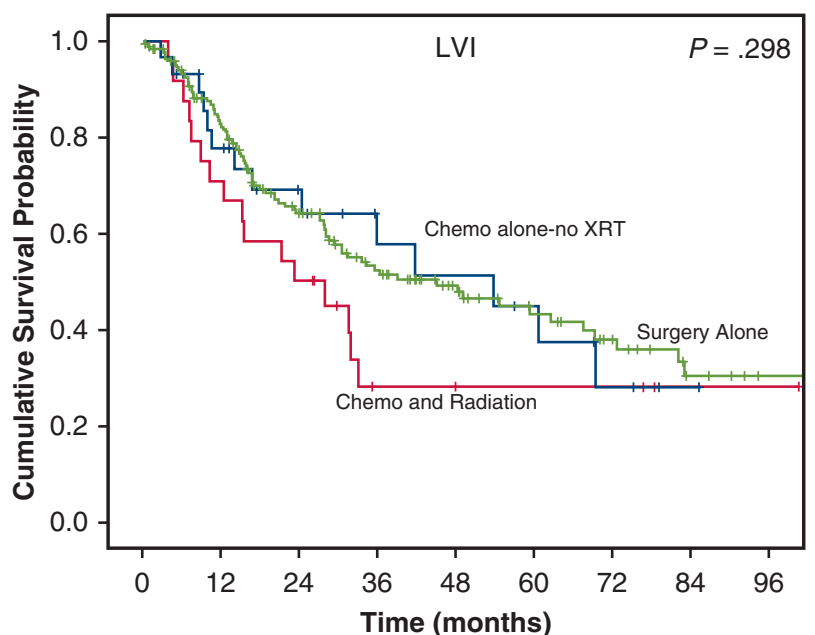

Number at Risk:

$\begin{array}{ccccccccc}170 & 125 & 88 & 57 & 37 & 26 & 19 & 10 & 6 \\ 29 & 20 & 14 & 10 & 8 & 6 & 3 & 1 & 0 \\ 24 & 17 & 12 & 4 & 3 & 3 & 3 & 1 & 1\end{array}$

B

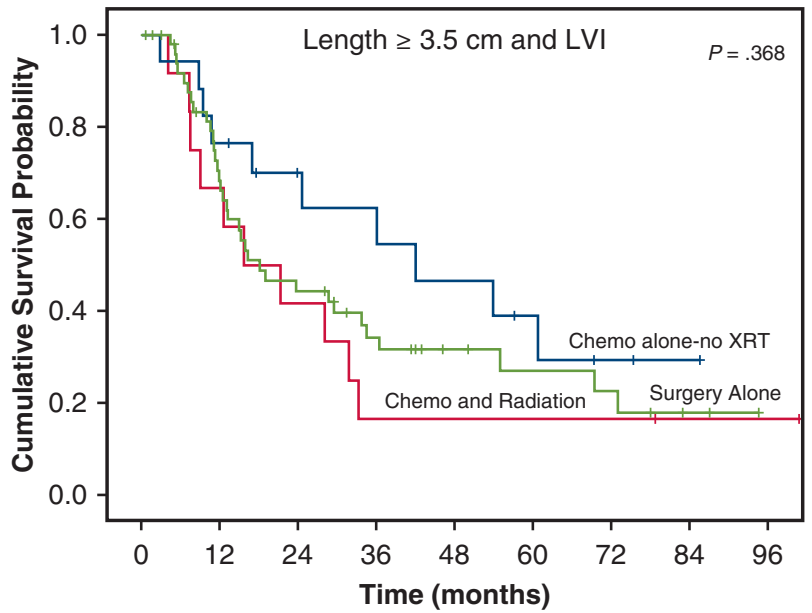

Number at Risk:

$\begin{array}{ccccccccc}52 & 33 & 20 & 13 & 8 & 6 & 5 & 2 & 0 \\ 17 & 13 & 9 & 8 & 6 & 4 & 2 & 1 & 0 \\ 12 & 8 & 5 & 2 & 2 & 2 & 2 & 1 & 1\end{array}$

D 
TABLE E1. Predictors of pN $>0$

\begin{tabular}{|c|c|c|c|c|}
\hline \multirow[b]{2}{*}{ Variable } & \multicolumn{2}{|c|}{ Univariable } & \multicolumn{2}{|c|}{ Multivariable } \\
\hline & OR (CI) & $P$ value & OR (CI) & $P$ value \\
\hline Age & $1(0.99-1.01)$ & .699 & $1(0.98-1.01)$ & .652 \\
\hline Histology & & .052 & & .659 \\
\hline Adenocarcinoma & 1 & & 1 & \\
\hline Squamous & $0.67(0.045-1.00)$ & & $0.86(0.43-1.72)$ & \\
\hline Location & & .135 & & .422 \\
\hline Upper-middle one-third & 1 & & 1 & \\
\hline Lower one-third-GEJ & $1.61(0.86-3.00)$ & & $1.56(0.52-4.67)$ & \\
\hline Sex & & .25 & & .474 \\
\hline M & 1 & & 1 & \\
\hline $\mathrm{F}$ & $0.78(0.51-1.19)$ & & $0.77(0.46-1.28)$ & \\
\hline Length & & $<.001$ & & .007 \\
\hline$<3.25 \mathrm{~cm}$ & 1 & & 1 & \\
\hline$\geq 3.25 \mathrm{~cm}$ & $2.97(1.81-4.87)$ & & $2.23(1.24-4.02)$ & \\
\hline
\end{tabular}

$O R$, Odds ratio; $C I$, confidence interval; $G E J$, gastroesophageal junction; $M$, male; $F$, female.

TABLE E2. Frequency of nodal involvement

\begin{tabular}{|c|c|c|c|}
\hline pN status & $\frac{>3.5 \mathrm{~cm}}{\mathrm{~N}=146(\%)}$ & $\frac{\text { LVI }}{N=170(\%)}$ & $\frac{>3.5 \mathrm{~cm}+\text { LVI }}{\mathrm{N}=52(\%)}$ \\
\hline $\mathrm{pN}=0$ & $58(40)$ & $69(41)$ & $4(8)$ \\
\hline $\mathrm{pN}>0$ & $88(60)$ & $101(59)$ & 48 (92) \\
\hline
\end{tabular}

LVI, Lymphovascular invasion. 
TABLE E3. Predictors of pN $>0$

\begin{tabular}{|c|c|c|c|c|}
\hline \multirow[b]{2}{*}{ Variable } & \multicolumn{2}{|c|}{ Univariable } & \multicolumn{2}{|c|}{ Multivariable } \\
\hline & OR (CI) & $P$ value & OR (CI) & $P$ value \\
\hline Age & $1(0.985-1.016)$ & .943 & $1(0.971-1.018)$ & .62 \\
\hline Histology & & .31 & & .578 \\
\hline Adenocarcinoma & 1 & & 1 & \\
\hline Squamous & $0.73(0.0405-1.330)$ & & $1.29(0.523-3.203)$ & \\
\hline Location & & .147 & & .133 \\
\hline Upper-middle one-third & 1 & & 1 & \\
\hline Lower one-third-GEJ & $1.75(0.822-3.708)$ & & $2.43(0.761-7.708)$ & \\
\hline LVI & & $<.001$ & & $<.001$ \\
\hline No & 1 & & 1 & \\
\hline Yes & $5.73(3.679-8.925)$ & & $6.65(3.943-11.20)$ & \\
\hline Sex & & .27 & & .703 \\
\hline M & 1 & & 1 & \\
\hline $\mathrm{F}$ & $0.78(0.501-1.214)$ & & $0.88(0.454-1.702)$ & \\
\hline Length & & $<.001$ & & $<.001$ \\
\hline$<3.5 \mathrm{~cm}$ & 1 & & 1 & \\
\hline$\geq 3.5 \mathrm{~cm}$ & $3.17(2.091-4.804)$ & & $4.32(2.512-7.431)$ & \\
\hline
\end{tabular}

$O R$, Odds ratio; $C I$, confidence interval; $G E J$, gastroesophageal junction; $L V I$, lymphovascular invasion; $M$, male; $F$, female. 
TABLE E4. Predictors of mortality

\begin{tabular}{|c|c|c|c|c|}
\hline \multirow[b]{2}{*}{ Variable } & \multicolumn{2}{|c|}{ Univariable } & \multicolumn{2}{|c|}{ Multivariable } \\
\hline & HR (CI) & $P$ value & HR (CI) & $P$ value \\
\hline Age & $1.028(1.023-1.033)$ & $<.001$ & $1.025(1.01-1.04)$ & $<.001$ \\
\hline pT & & $<.001$ & & \\
\hline T0-Tis & 1 & & 1 & \\
\hline $\mathrm{T} 1$ & $0.85(0.44-1.67)$ & & $0.89(0.34-2.30)$ & .805 \\
\hline $\mathrm{T} 2$ & $1.38(0.74-2.58)$ & & $1.13(0.47-2.71)$ & .792 \\
\hline $\mathrm{T} 3$ & $2.90(1.54-5.49)$ & & $1.98(0.79-4.99)$ & .148 \\
\hline $\mathrm{T} 4$ & $6.57(2.94-14.7)$ & & $3.97(0.86-18.3)$ & .077 \\
\hline $\mathrm{pN}$ & & $<.001$ & & \\
\hline NO & 1 & & 1 & \\
\hline N1 & $2.12(1.64-2.73)$ & & $1.71(1.20-2.43)$ & .003 \\
\hline $\mathrm{N} 2$ & $3.74(2.89-4.84)$ & & $2.61(1.86-3.65)$ & $<.001$ \\
\hline N3 & $5.83(2.92-11.64)$ & & $4.27(2.20-8.27)$ & $<.001$ \\
\hline $\mathrm{pM}$ & & $<.001$ & & \\
\hline M0 & 1 & & 1 & \\
\hline M1 & $11.4(4.90-26.6)$ & & $5.59(2.53-12.4)$ & .001 \\
\hline Histology & & .231 & & \\
\hline Adenocarcinoma & 1 & & 1 & \\
\hline Squamous & $1.24(0.87-1.75)$ & & $1.55(1.12-2.15)$ & .008 \\
\hline Location & & .507 & & \\
\hline Upper-middle one-third & 1 & & 1 & \\
\hline Lower one-third-GEJ & $1.15(0.87-1.75)$ & & $1.20(0.73-1.96)$ & .467 \\
\hline Type of resection & & .01 & & \\
\hline Right transthoracic & 1 & & 1 & \\
\hline Transhiatal & $1.35(0.75-2.43)$ & .077 & $1.31(0.78-2.22)$ & .312 \\
\hline McKeown & $1.51(1.15-1.97)$ & .005 & $1.32(1.04-1.67)$ & .021 \\
\hline MIE & $1.32(1.04-1.69)$ & .150 & $1.59(1.27-2.00)$ & $<.001$ \\
\hline Left transthoracic & $0.76(0.49-1.20)$ & .192 & $0.65(0.30-1.42)$ & .281 \\
\hline N/A & $0.97(0.66-1.43)$ & .957 & $1.01(0.62-1.65)$ & .969 \\
\hline Preoperative treatment & & .981 & & \\
\hline CXRT & 1 & & 1 & \\
\hline Chemo alone & $1.03(0.68-1.56)$ & .879 & $0.58(0.37-0.92)$ & .020 \\
\hline No treatment & $1.04(0.69-1.56)$ & .845 & $0.92(0.64-1.31)$ & .642 \\
\hline Tumor length & $1.07(0.98-1.17)$ & .136 & $1.02(0.93-1.11)$ & .714 \\
\hline Sex & & .538 & & .574 \\
\hline M & 1 & & 1 & \\
\hline $\mathrm{F}$ & $0.92(0.71-1.20)$ & & $1.09(0.81-1.47)$ & .574 \\
\hline
\end{tabular}

HR, Hazard ratio; $C I$, confidence interval; GEJ, gastroesophageal junction; $M I E$, minimally invasive esophagectomy; N/A, not available; $C X R T$, chemoradiation; $M$, male; $F$, female.

TABLE E5. Median survival estimates

\begin{tabular}{|c|c|c|c|c|c|}
\hline & \multicolumn{3}{|c|}{ Pretreatment group } & \multirow[b]{2}{*}{ Overall } & \multirow[b]{2}{*}{$P$ value } \\
\hline & CXRT & Chemo & Surgery alone & & \\
\hline Length $>3.5 \mathrm{~cm}$ & $71(45-98)$ & $57(28-85)$ & $34(20-49)$ & $49(36-62)$ & .25 \\
\hline $\mathrm{pN}>0$ & $21(10-32)$ & $31(17-44)$ & $31(24-39)$ & $31(25-36)$ & .211 \\
\hline LVI & $23(5-42)$ & $54(22-85)$ & $45(26-64)$ & $36(23-49)$ & .298 \\
\hline Length $>3.5 \mathrm{~cm}+$ LVI & $16(1-30)$ & $42(9-75)$ & $18(7-29)$ & $24(11-36)$ & .368 \\
\hline
\end{tabular}

Values are months $(95 \% \mathrm{CI})$. CXRT, Chemoradiation; $L V I$, lymphovascular invasion. 